\title{
Robust Design of RF-MEMS Cantilever Switches Using Contact Physics Modeling
}

\author{
Mohammed M. Shalaby, Zhongde Wang, Member, IEEE, Linda L.-W. Chow, Member, IEEE, Brian D. Jensen, \\ John L. Volakis, Fellow, IEEE, Katsuo Kurabayashi, Member, IEEE, and Kazuhiro Saitou, Senior Member, IEEE
}

\begin{abstract}
This paper presents the robust design optimization of an RF-MEMS direct contact cantilever switch for minimum actuation voltage and opening time, and maximum power handling capability. The design variables are the length and thickness of the entire cantilever, the widths of the sections of the cantilever, and the dimple size. The actuation voltage is obtained using a 3-D structural-electrostatic finite-element method (FEM) model, and the opening time is obtained using the same FEM model and the experimental model of adhesion at the contact surfaces developed in our previous work. The model accounts for an unpredictable variance in the contact resistance resulting from the micromachining process for the estimation of the power handling. This is achieved by taking the ratio of the root mean square power of the RF current ("signal") passing through the switch to the contact temperature ("noise") resulting from the possible range of the contact resistance. The resulting robust optimization problem is solved using a Strength Pareto Evolutionary Algorithm, to obtain design alternatives exhibiting different tradeoffs among the three objectives. The results show that there exists substantial room for improved designs of RF-MEMS direct-contact switches. It also provides a better understanding of the key factors contributing to the performances of RF-MEMS switches. Most importantly, it provides guidance for further improvements of RF-MEMS switches that exploit complex multiphysics phenomena.
\end{abstract}

Index Terms-Contact physics, radio-frequencymicroelectromechanical-systems (RF-MEMS) switches, robust design.

\section{INTRODUCTION}

$\mathbf{T}$ HE introduction of microelectromechanical systems (MEMS) technology to conventional microwave inte-

Manuscript received April 23, 2008; revised September 4, 2008. First published October 31, 2008; current version published April 1, 2009. This work was supported by the National Science Foundation.

M. M. Shalaby was with the University of Michigan, Ann Arbor, MI 48109 USA. He is now with the Mechanical Integration and Operability Laboratory, Global Research Center, General Electric Company, Niskayuna, NY 12309 USA (e-mail: shalaby@ge.com).

Z. Wang was with the University of Michigan, Ann Arbor, MI 48109 USA. He is now with Ansoft Corporation, San Jose, CA 95129 USA (e-mail: zwang@ansoft.com).

L. L.-W. Chow was with the University of Michigan, Ann Arbor, MI 48109 USA. She is now with Intel Corporation, Phoenix, AZ 85226 USA (e-mail: linda.1.chow@intel.com).

B. D. Jensen is with the Department of Mechanical Engineering, Brigham Young University, Provo, UT 84602 USA (e-mail: bdjensen@byu.edu).

J. L. Volakis is with the Department of Electrical and Computer Engineering, The Ohio State University, Columbus, OH 43212 USA (e-mail: volakis@ece.osu.edu).

K. Kurabayashi and K. Saitou are with the Department of Mechanical Engineering, University of Michigan, Ann Arbor, MI 48109 USA (e-mail: katsuo@umich.edu; kazu@umich.edu).

Color versions of one or more of the figures in this paper are available online at http://ieeexplore.ieee.org.

Digital Object Identifier 10.1109/TIE.2008.2006832 grated circuit processing enabled a new class of radio-frequency (RF) micromechanical switches [1]. RF-MEMS direct contact switches possess superior characteristics such as wideband, ultralow loss, high linearity, and negligible power consumption [2]. Typically, less than $0.1-\mathrm{dB}$ loss from dc to $100 \mathrm{GHz}$ with power consumption on the order of microwatts is obtained by using high conductivity metallic materials [3], [4]. Such wideband low-loss switches can be used in radar and communication antennas [5]-[9] and tunable filters [8]-[12].

However, they also often suffer from several unfavorable drawbacks including high actuation voltage, low power handling capability, and long opening time [13]. Nonetheless, these switching characteristics can be improved by selecting appropriate switch designs and operational conditions. The geometry and structural properties of the switch body, both of which influence its stiffness, determine the actuation voltage, i.e., the dc voltage applied to pull the switch body down to an operational contact state. There exists a strong correlation between the power handling capability and contact reliability of the switches. The contact reliability is highly affected by the temperature of the contact surfaces. For switches made of sputtered gold, the temperature should be maintained between $60^{\circ} \mathrm{C}$ and $80^{\circ} \mathrm{C}$, since the lower temperatures cause unbounded increase in contact resistance [14], whereas higher temperatures cause the melting and welding of the contact surfaces. These phenomena occurring outside the desirable temperature range result in the permanent failure of the switches. The opening time, i.e., the time for the switch contact surfaces to experience complete physical separation after the actuation voltage is turned off, is governed by the size of the contact dimple as it influences the adhesion force between the contact surfaces.

This paper presents the design optimization of RF-MEMS direct contact cantilever switches (Fig. 1) to achieve minimum actuation voltage and opening time, while maximizing power handling. The design variables are the length and thickness of the entire cantilever, the widths of the cantilever sections, and the dimple size. The finite element method (FEM) combined with an experimental model of adhesion at the contact surfaces [15] are used to evaluate the following objectives: 1) the actuation voltage; 2) the switch opening time; and 3) the power handling capability. Here, the power handling capability is defined as the maximum allowable RF power that can be sustained by the switch body without causing the contact temperature outside the aforementioned range. Here, the contact temperature is determined by the contact resistance value. However, it is difficult to uniquely determine it due to uncontrollable variations in the contact resistance during the 


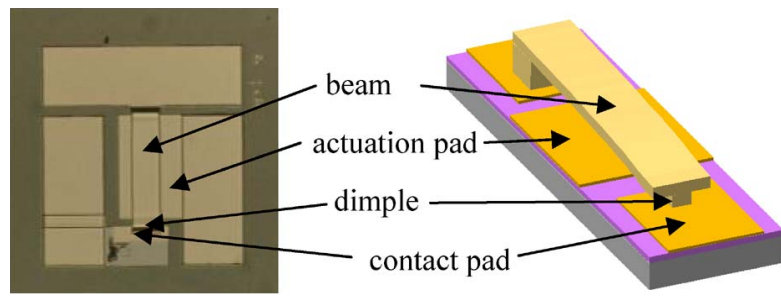

Fig. 1. RF-MEMS direct contact cantilever switch.

actual micromachining processes. Therefore, we employ the signal-to-noise ratio model [16], [17] to estimate the power handling. In this model, the signal value is the root mean square (rms) power of the RF current passing through the switch, whereas the noise is the contact temperature resulting from the uncertainty in the contact resistance value. The resulting robust optimization problem is solved using a Strength Pareto Evolutionary Algorithm (SPEA) [18]-[20], to obtain Paretooptimal design alternatives exhibiting different tradeoffs among the three objectives.

\section{RELATED WORK}

\section{A. Characterization and Modeling of RF-MEMS Switches}

A number of researchers have studied the performance of RF-MEMS switches and pointed out some unfavorable drawbacks. Chan et al. [21] and Goldsmith et al. [22]-[24] indicated that a high actuation voltage may lead to a shorter lifetime for direct contact and capacitive MEMS switches which use dielectric layers for isolation. Schauwecker et al. [25] and Rebeiz and Muldavin [26] point out that that the power handling capability is often lower than $100 \mathrm{~mW}$, whereas most wireless applications may require $1 \mathrm{~W}$.

The electromagnetic modeling of RF-MEMS switches is a challenging task due to the tiny electrical dimensions and the switch motion during the operation [27]. Some papers suggest solutions to these challenges, such as finite difference time domain [28] and moment method [1], [29]. Wang et al. [27] developed an extended finite-element boundary-integral (EFE-BI) method by applying a conventional FE-BI [29] on the substrate and a BI for the switch beam. This model was experimentally verified by Chow et al. [30] for air-suspended transmission lines. A closed-form thermal model capturing the skin effect was employed in [27] and [30]. This latter model saves computational time and demonstrates very reasonable accuracy and is therefore adopted in this paper.

\section{B. Contact Modeling for RF-MEMS Switches}

Understanding the thermal and mechanical behavior of contact surfaces is the key to improving the performance, reliability, and power handling of RF-MEMS direct contact switches. Greenwood and Williamson developed a classical model of contact heating in 1958 based on the assumption that equipotential surfaces are coincident with the isotherms in the contact [31]. In our previous work, Jensen et al. [15] extended the model and further demonstrated the control of the contact resistance by a softening temperature. When the contact temperature exceeds the contact material softening temperature, the contact resistance drops drastically and remains low.

As expected, switch opening time is highly affected by adhesion, and most models and experiments have focused on steady-state behavior. More recently, Jensen et al. developed a kinetic model, and therefore, this model will be adopted in this paper.

\section{RF-MEMS Switch Optimization}

A number of efforts have already been published on RFMEMS optimization. Among them, Ducarouge et al. [32] developed a design method for fixed-fixed RF-MEMS switches and optimized the beam by varying three width variables. Miao et al. [33] controlled the performance of a capacitive fixed-fixed RF-MEMS switch by changing the geometry at both ends of the beam to have smaller widths, thus reducing the switch stiffness. Huang et al. [34] pursed a more general approach by dividing the beam into several sections, each with a different width and length to have more control on the switch performance. The artificial neural network method was then used to simulate and optimize the beam [35]. The input variables were the beam length and width at each beam section with the insertion and return loss as the output variables.

Nevertheless, none of the aforementioned models dealt with cantilever RF-MEMS switches which are known to have better structural properties and are less prone to buckling. Furthermore, previous optimization models only handled one to three design objectives and few design variables.

\section{Robust Design Optimization}

Taguchi [16] defined robustness as the "insensitivity of the system performance to parameters that are uncontrollable by the designer." A robust design incorporates this concept of robustness into design optimization and aims at achieving designs that optimize given performance measures while minimizing sensitivities against uncontrollable parameters using different approaches, such as signal to noise ratio [36]-[40].

A key system parameter affecting power handling in RF-MEMS switches is contact resistance. This parameter is virtually impossible to precisely control during micromachining. Thus, in the following, we focus on design optimization with the contact resistance being a free parameter.

\section{Robust Optimization OF RF-MEMS SwitcheS}

\section{A. Overview}

The optimization problem statement for RF-MEMS direct contact cantilever switches can be summarized as follows:

- Given: switch material properties (mechanical, electrical, and thermal including), geometry of one side of cantilever beam with parameters for optimization, contact dimple, gap length between the switch beam and the substrate, and the acceptable range of contact resistance.

- Find: beam and dimple dimensions, and RF current.

- Subject to: a feasible contact temperature accounting for contact resistance variations. 


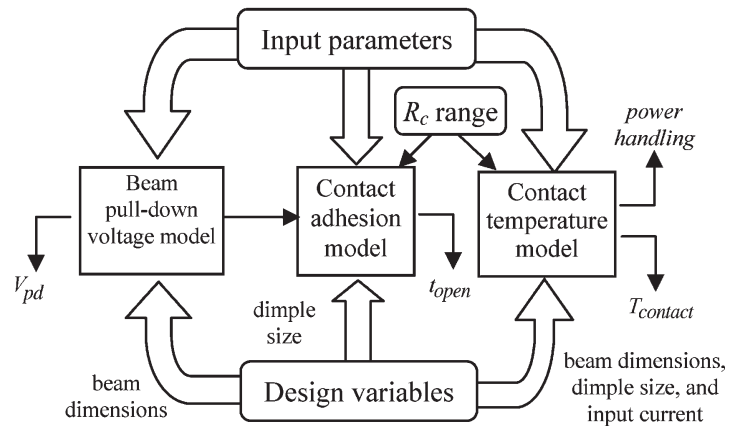

Fig. 2. Inputs and outputs of models used.

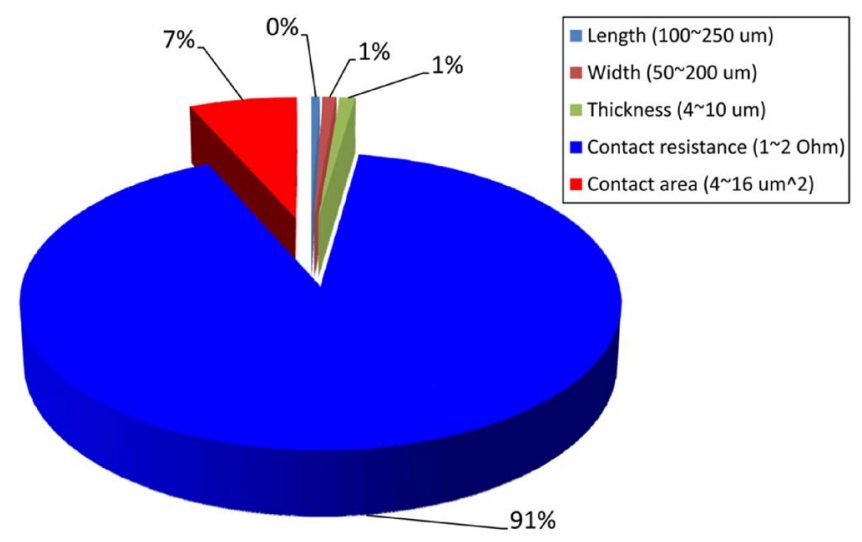

Fig. 3. Power handling capability factors.

- Minimize: actuation voltage and switch opening time.

- Maximize: switch power handling.

The optimization problem is set up via a SPEA to obtain Pareto-optimal design alternatives exhibiting different tradeoffs among the three objectives: actuation voltage, switch opening time, and power handling capability.

Fig. 2 shows the input-output relationships between the mathematical models used to compute the three objectives. Three different computational models are employed within the optimization loop. The actuation voltage $\left(V_{\mathrm{pd}}\right)$ is obtained using a 3-D structural-electrostatic FE beam model; the switch opening time $\left(t_{\text {open }}\right)$ evaluation is based on an experimental contact adhesion model from our previous work [15]. This model accounts for the dimple size, contact resistance, and the restoring force $\left(F_{\text {restore }}\right)$ of the beam at the down state. Finally, for power handling evaluation, an analytical model based on a 2-D thermal FE model was adopted.

A sensitivity analysis was made to check the effect of varying the beam's dimensions, dimple size, and contact resistance on the power handling capability. The results are shown in Fig. 3 (referring to a typical beam with dimensions of $200 \times 100 \times$ $7 \mu \mathrm{m}$, dimple size of $10 \mu \mathrm{m}^{2}$, contact resistance of $1.5 \Omega$, and contact roughness of $20 \mathrm{~nm}$ ). From the pie chart, we note that varying the contact resistance highly affects power handling, whereas the effect of varying the beam dimensions and dimple size can be neglected. As a result, the robust optimization will only consider the variation in the contact resistance.

We remark that, because $t_{\text {open }}$ and $T_{\text {contact }}$ are dependent on the contact resistance, which is uncontrollable, we used robust optimization using signal to noise ratio to reduce the sensitivity

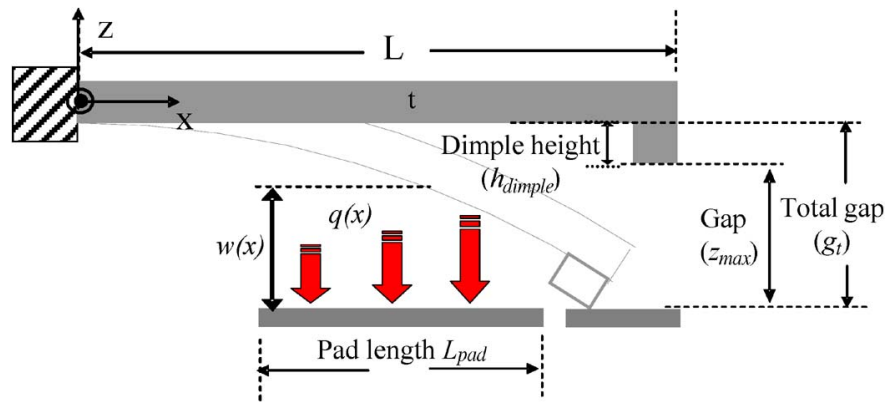

Fig. 4. Cross-sectional view of the cantilever beam.

of the results to the contact resistance as discussed in detail in Section III-F.

In the following, we discuss each of these models in more detail before proceeding with the integration into the multiphysics design optimization loop.

\section{B. Structural/Electrostatic Model}

Fig. 4 shows a cross-sectional view of a cantilever switch. When the actuation voltage is applied to the pad, electrostatic fields at the gap between the beam and the pad generate an electrostatic force $q(x)$ along the beam length. This causes a vertical beam displacement $w(\boldsymbol{x})$. The relation between the electrostatic force $q(\boldsymbol{x})$ and the beam displacement $w(\boldsymbol{x})$ is approximately given by (1)-(5) [41]

$$
\begin{aligned}
q & =\frac{1}{2} V^{2} \frac{\partial c(w)}{\partial w}=\frac{1}{2} V^{2} \frac{c(w+\Delta w)-c(w-\Delta w)}{2 \Delta w} \\
c & =\frac{1}{Z_{c}(w) \sqrt{\mu_{0} \varepsilon_{0}}} \\
Z_{c}(w) & =\frac{1}{2 \pi} \sqrt{\frac{\mu_{0}}{\varepsilon_{0}}} \ln \left[F_{1} \frac{g_{t}+w}{b_{e}}+\sqrt{1+\left(2 \frac{g_{t}+w}{b_{e}}\right)^{2}}\right] \\
F_{1} & =6+(2 \pi-6) \exp \left\{-\left[30.666\left(g_{t}+w\right) / b_{e}\right]^{0.7528}\right\} \\
b_{e} & =b+\frac{t}{\pi}\left\{1+\ln \left[2 \frac{g t+w}{t}\right]\right\}
\end{aligned}
$$

where (see Fig. 4) $b$ is the beam width, $t$ is the beam thickness, $g_{t}$ is the total initial gap, $b_{e}$ is the effective beam width, $F_{1}$ is a numerical parameter (of no physical significance), $\mu_{0}=$ $4 \pi \times 10^{-7} \mathrm{H} / \mathrm{m}$ is the free space permeability, $\varepsilon_{0}=8.85 \times$ $10^{-12} \mathrm{~F} / \mathrm{m}$ is the free space permittivity, $Z_{c}(w)$ is the characteristic impedance of the equivalent microstrip line at the location where the displacement is $w$, and $\Delta w=1 \mathrm{~nm}$.

The minimum voltage that can deflect and close the beam is called the actuation voltage or pull-down voltage $\left(V_{\mathrm{pd}}\right)$. For the design considered in this paper, the total gap $g_{t}$ and the dimple height $h_{\text {dimple }}$ are chosen as 1.7 and $1.3 \mu \mathrm{m}$, respectively. These design choices ensure that the beam will be able to make contact without unstable pull-in, since the dimple height is more than $2 / 3$ of the total gap. In this design, the authors avoided using dielectric to avoid any change in the actuation voltage due to dielectric charging. Hence, with $V_{\text {pd }}$ applied, the beam end is barely touching the contact pad, making the reaction force to the dimple nearly zero. If the applied voltage is too small, the reaction force from the beam will be negative, meaning that 
TABLE I

COMPARISON OF OUR MODEL WITH CW

\begin{tabular}{llccccccc}
\hline \hline \multicolumn{2}{c}{ Applied Voltage $(\mathrm{V})$} & 4 & 8 & 10 & 12 & 16 & 20 & 24 \\
\hline \multirow{2}{*}{$F_{r}(\mu \mathrm{N})$} & $\mathrm{CW}$ & 0.073 & 0.320 & 0.794 & 0.983 & 1.463 & 2.135 & 3.083 \\
& Our model & 0.072 & 0.313 & 0.794 & 0.976 & 1.438 & 2.075 & 2.985 \\
$F_{c}(\mu \mathrm{N})$ & $\mathrm{CW}$ & $\mathrm{N}^{1} \mathrm{~A}^{1}$ & $\mathrm{~N} / \mathrm{A}^{1}$ & $\mathrm{~N} / \mathrm{A}^{1}$ & 0.084 & 0.506 & 1.097 & 1.960 \\
& Our model & $\mathrm{N}^{1} \mathrm{~A}^{1}$ & $\mathrm{~N} / \mathrm{A}^{1}$ & $\mathrm{~N} / \mathrm{A}^{1}$ & 0.085 & 0.505 & 1.098 & 1.949 \\
\hline \hline
\end{tabular}

${ }^{1}$ The applied voltage less than the pull-down voltage

additional force is needed to pull the switch to the "close" state. Similarly, when the applied voltage is high enough, the reaction force is positive, meaning that the switch is applying force on the contact pad.

The actuation voltage giving zero reaction to the dimple can be iteratively found as follows.

1) Apply an initial (artificial) displacement at the beam, such that the dimple touches the contact pad, and set the actuation voltage $V=V_{0}$ where $V_{0}$ is arbitrary.

2) Calculate the vertical displacement $w(\boldsymbol{x})$ using the structural model of beam deflection.

3) Calculate electrostatic force $q(\boldsymbol{x})$ for $w(\boldsymbol{x})$ and $V$ using the electrostatic model (1)-(5).

4) If the reaction force at the dimple $F_{\text {react }}<0$, increase $V$. If $F_{\text {react }}>0$, decrease $V$. Otherwise return $V$.

5) Go to 2).

We remark that a combination of the bisection, secant, and inverse quadratic interpolation methods [42], [43] were used at step 4) to find the next iterate for $V$.

The restoring force $\left(F_{\text {restore }}\right)$ necessary for the switch opening time is also obtained by calculating $F_{\text {react }}$ with zero actuation voltage.

Table I shows a comparison of our method with the commercial code CoventorWare $(\mathrm{CW})$ for the reaction force $\left(F_{r}\right)$ at the fixed support and at the dimple (contact force $F_{c}$ ) with different applied voltages (for a switch having $L=200 \mu \mathrm{m}, b=20 \mu \mathrm{m}$, $t=2 \mu \mathrm{m}, g=2 \mu \mathrm{m}, L_{\text {pad }}=160 \mu \mathrm{m}$, material gold with $E=78 \mathrm{GPa}$, and $\nu=0.44)$. The results agree quite well.

\section{Contact Adhesion Model}

Assuming gold as the contact material, the following differential equation can be used to determine the number of gold-gold bonds on the contact area [14]:

$$
\frac{\partial N_{2}}{\partial \mathrm{ti}}=-N_{2} k_{02} \exp \left[\frac{K_{2} F_{\text {restore }} x_{2}}{k_{B} T\left(\phi_{1} A_{a}+K_{2} N_{2}\right)}\right] .
$$

Here, $N_{2}$ is the number of gold-gold bonds at a certain time ti, $k_{02}$ is the bond dissociation rate constant, $K_{2}$ is the gold-gold bond stiffness [36], $F_{\text {restore }}$ represents the restoring force acting to open the contact obtained using the beam pulldown model, $x_{2}$ is a numerical parameter roughly equivalent to the gold-gold bond distance before breaking, $k_{B}$ is the Boltzmann constant, $T$ is the temperature, $\phi_{1}$ is a numerical parameter describing the density and stiffness of bonds other than the gold-gold bonds, and $A_{a}$ is the apparent contact area, typically the area of the contact dimple in a switch. One may state that $t_{\text {open }}$ is the time needed for all gold bonds
TABLE II

Values of Parameters Used to Model Contact OPEning Time [14]

\begin{tabular}{lll}
\hline \hline Parameter & Value & Unit \\
\hline$k_{02}$ & $3.52 \times 10^{-3}$ & $\mathrm{~ms}^{-1}$ \\
$x_{2}$ & 0.021 & $\mathrm{~nm}$ \\
$\phi_{1}$ & 12,320 & $\mu \mathrm{N} / \mu \mathrm{m}^{3}$ \\
$K_{2}$ & 12 & $\mathrm{~N} / \mathrm{m}$ \\
$\rho_{2}$ & $12 \times 10^{6}$ & Bonds $/ \mu \mathrm{m}^{2}$ \\
$\lambda$ & 38 & $\mathrm{~nm}$ \\
$\rho_{\mathrm{e}}$ & $3.6 \times 10^{-6}$ & $\Omega-\mathrm{m}$ \\
\hline
\end{tabular}

to dissociate between the contact surfaces (and thus open). Equation (6) is solved numerically using the initial condition

$$
N_{2_{0}}=\rho_{2}\left(\pi a^{2}\right)
$$

In which, $\rho_{2}$ is the initial area density of the gold-gold bonds, and $a$ is the radius of the actual contact spot. We remark that the theoretical contact resistance value is related to $a$ by the following [45]:

$$
R_{c}=\frac{4 \rho_{e} \lambda}{3 \pi a^{2}}+\left[\frac{1+0.83(\lambda / a)}{1+1.33(\lambda / a)}\right] \frac{\rho_{e}}{2 a}
$$

where $R_{c}$ is the contact resistance, $\rho_{e}$ is the metal's electrical resistivity (assumed to be the same for both contact surfaces), and $\lambda$ is the mean free path of the electron. Nevertheless, in practice, the contact resistance is not deterministic, due to manufacturing inaccuracies. During manufacturing, we can adjust the manufacturing parameters to obtain $R_{c}=1.5 \Omega$; yet, in reality, it would range between 1.3 and 1.7. To solve (6), we take $R_{c}=1.5 \Omega$, which is the median value of $R_{c}$, and refer the reader to [27] and [15] for the other parameter values. The values of all parameters used in this paper are summarized in Table II.

\section{Contact Temperature Model}

Joule heating is primarily caused by the electric resistance. For switches made of sputtered gold, the temperature should be maintained between $60^{\circ} \mathrm{C}$ and $80^{\circ} \mathrm{C}$, (since lower temperatures cause an unbounded increase in contact resistance [11] and higher temperatures cause melting and welding of the contact surfaces). Basically, temperature controls resistance which, in turn, causes switch failure.

The current flow in the switch causes Joule heating in accordance with the heat transfer equation

$$
-\kappa \nabla^{2} T=P_{d}=J^{2} \rho
$$

where $\kappa$ refers to thermal conductivity, $T$ is temperature, $P_{d}$ represents dissipated electrical power, $J$ is the RF current density, and $\rho$ is the electrical resistivity. We shall assume that the temperature varies negligibly across the thickness of the beam as compared with the beam length and width. Thus, a 2-D finite element model was used and found sufficient. The additional heat generated at the contact due to the contact resistance $R_{c}$ is simply added to the heat generation of the finite elements on the contact surfaces. This heat is approximated as $I_{0}^{2} R_{c} / 2$, where $I_{0}$ is the rms RF current. Furthermore, since the electrical signal 


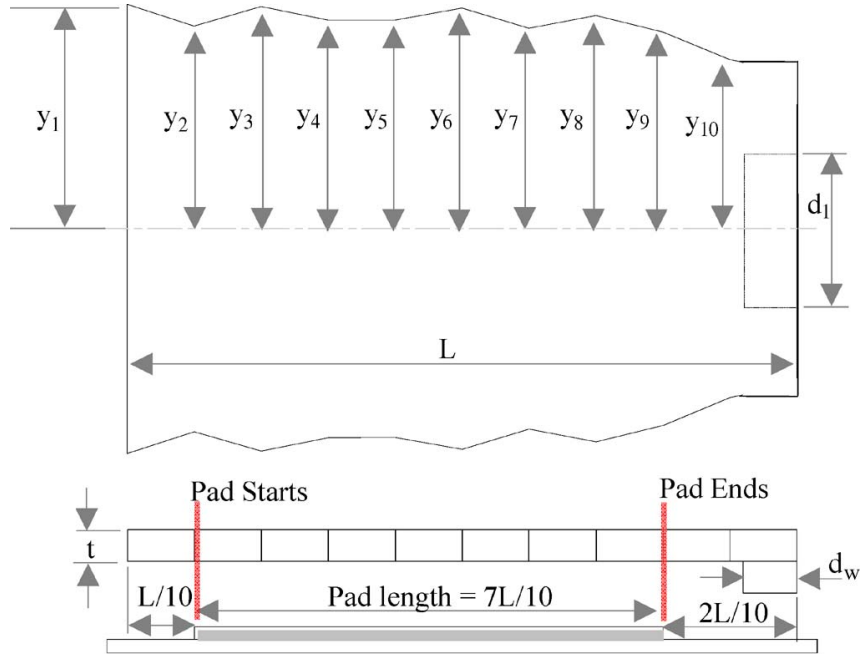

Fig. 5. Switch geometry and design variables.

period is sufficiently smaller than the thermal response time, we can assume a constant rms current in solving (9).

Taking into account the high-frequency effect [48], the contact temperature can be approximated by [31]

$$
T_{\text {contact }}=\sqrt{\frac{\gamma\left(R_{m} / R_{c}\right) V^{2}}{4 L}+\frac{T_{2}^{2}+T_{0}^{2}}{2}}-T_{0}
$$

where $T_{2}$ is the average temperature over the dimple obtained by solving (9), $T_{0}$ is the ambient temperature at the substrate, $L=2.45 \times 10^{-8} \mathrm{~V}^{2} / \mathrm{K}^{2}$ is the Lorentz constant, $V=I_{0} R_{c}$ is the voltage drop across the contact, $R_{c}$ refers to the contact resistance, $R_{m}=(\rho / 2 a) \mu \Omega, a$ is the radius of the contact spot, $\gamma=(1+0.83(\lambda / a)) /(1+1.33(\lambda / a))$, and $\rho=3.58 \times$ $10^{-8} \Omega \cdot \mathrm{m}$ is the gold conductivity.

Equation (10) shows that the contact temperature is mainly dependent on the electrical contact resistance (typically between 1 and $2 \Omega$ ), the RF current, and the dimple area. Our earlier work [49] indeed confirmed that a larger dimple area decreases thermal resistance and, in turn, decreases contact temperature. Thus, since $T_{\text {contact }}$ in (10) must lie between $60{ }^{\circ} \mathrm{C}$ and $80^{\circ} \mathrm{C}$, the RF current and the dimple area must be controlled to achieve this $T_{\text {contact }}$ range.

\section{E. Design Variables}

There are 15 design variables as shown in the following:

1) $y_{1}, \ldots, y_{10}$ : widths of the beam sections along its length;

2) $L, t$ : beam length and thickness, respectively;

3) $d_{l}, d_{w}$ : dimple length and width, respectively;

4) $I_{0}: R F$ current (in rms).

The design variables are shown in Fig. 5. We remark that the actuation pad always starts at $L / 10$ and ends at $8 L / 10$ from the anchor. Since power handling is directly proportional to $I_{0}^{2}$, $\mathrm{RF}$ current $I_{0}$ is regarded as one of the design variables, and its power, not the RF power input, is regarded as one of the design objectives to be maximized.

\section{F. Design Objectives}

We aim to design RF-MEMS switches with low pull-down voltage $V_{\mathrm{pd}}$, short opening time $t_{\mathrm{open}}$, and high power handling or equivalently capable of large RF current $I_{0}$. While $I_{0}$ is a design variable, it has an upper bound since the contact temperature $T_{\text {contact }}$ depends on $I_{0}$ and it must lie between $60{ }^{\circ} \mathrm{C}$ and $80^{\circ} \mathrm{C}$. Nevertheless, $t_{\text {open }}$ and $I_{0}^{2}$ cannot be used as objectives since they depend on the uncontrollable parameter contact resistance $R_{c}$. $R_{c}$ can be kept between 1.3 and $1.7 \Omega$ by the proper control of the contact material and insulating film [14]. Thus, these objectives have to be modified to reduce their sensitivity to $R_{c}$. In an effort to do so and using the signal to noise ratio method [16], [38], we define the opening time robustness objective $f_{2}$ and power handling robustness objective $f_{3}$. We choose the signal parameters as $t_{\text {open } @ R_{c}=1.5}$ and $I_{0}^{2}$ while minimizing the noise parameters as $\Delta t_{\text {open }}$ (11) and $\Delta T_{\text {contact }}(12)$, since $T_{\text {contact }}$ is proportional to $I_{0}^{2}$. We remark that the noise equations are formulated as given in (11) and (12) because $t_{\text {open }}$ and $T_{\text {contact }}$ vary monotonically with respect to $R_{c}$

$$
\begin{aligned}
\Delta t_{\text {open }} & =t_{\text {open } @ R_{c}=1.3}-t_{\text {open } @ R_{c}=1.7} \\
\Delta T_{\text {contact }} & =T_{\text {contact } @ R_{c}=1.7}-T_{\text {contact } @ R_{c}=1.3 .} .
\end{aligned}
$$

In summary, our optimization problem can be stated as follows:

- minimize: $f_{1}, f_{2}$

- maximize: $f_{3}$

where

$$
\begin{aligned}
& f_{1}=V_{\text {pull-in }}=V\left(y_{1}, \ldots, y_{10}, L, t\right) \\
& f_{2}=t_{\text {open } @ R_{c}=1.5} \bullet \Delta t_{\text {open }} \\
& f_{3}=\frac{I_{0}^{2}}{\Delta T_{\text {contact }}}
\end{aligned}
$$

subject to the following constraints:

$$
\begin{aligned}
10 & \leq y_{1}, \ldots, y_{10} \leq 75 \mu \mathrm{m} \\
200 & \leq L \leq 400 \mu \mathrm{m} \\
0.5 & \leq t \leq 5 \mu \mathrm{m} \\
1.1 & \leq d_{l}, d_{w} \leq 10 \mu \mathrm{m} \\
10 & \leq I_{0} \leq 1000 \mathrm{~mA} \\
V_{\text {pull-in }} & \leq 80 \mathrm{~V} \\
t_{\text {open }} & \leq 100 \mu \mathrm{s} \\
60 & \leq T_{\text {open } @ R_{c}=1.3}, T_{\text {open } @ R_{c}=1.7} \leq 80{ }^{\circ} \mathrm{C} .
\end{aligned}
$$

The upper and lower bounds of the beam widths, lengths, and thicknesses are obtained based on the micromachining capabilities available. The lower bound on $d_{w}$ and $d_{l}$ is set to the skin depth at a typical operational frequency of $5 \mathrm{GHz}$ to confine all RF energy without any radiation. The pull-in voltage and the opening time are constrained not to exceed their practical values.

\section{G. Optimization Algorithm}

Since the aforementioned optimization problem is multiobjective (three objectives to optimize), we adopted SPEA [18], 
TABLE III

PARAMETERS FOR SPEA

\begin{tabular}{lr}
\hline \hline \multicolumn{1}{c}{ Parameter } & Value \\
\hline Population size & 100 \\
Number of generations & 120 \\
External population size & 50 \\
Crossover probability & 0.50 \\
Mutation probability & 0.15 \\
\hline \hline
\end{tabular}

[20] to find the tradeoff among the various conflicting design objectives. SPEA has several advantages over the conventional multiobjective genetic algorithms, namely, 1) dominating solutions are sorted externally in a second continuously updated population, 2) the fitness of each individual in the normal population is evaluated with respect to the number of dominating points in the external population that dominate that individual, 3) Pareto dominance preserves the population diversity, and 4) a clustering procedure is used to reduce the dominating set without destroying its characteristics [18]. In the implementation of SPEA, side constraints (16)-(20) are embedded in the chromosome encoding of the algorithm, whereas constraints (21)-(23) are handled as penalties on their objective functions. The parameters used in the SPEA are summarized in Table III.

\section{RESUlTS AND DisCUSSION}

The resulting 2-D projections of the Pareto optimal solutions are shown in Fig. 6(a)-(c).

We note that these solutions correspond to similar values of $L=200 \mu \mathrm{m}$, beam thickness $t=5 \mu \mathrm{m}$, dimple width $d_{w}=$ $1.1 \mu \mathrm{m}$, and RF current $I_{0}=53.5 \mathrm{~mA}$. As expected, when the beam thickness increases, switch stiffness increases, resulting in smaller switch opening times. This could be the reason that the Pareto solutions correspond to the thickness upper bound $t=5 \mu \mathrm{m}$. The optimizer also tries to maximize the beam width at the actuation pad, to maximize the area affected by the voltage; thus, the pull-down force is also maximized, for the same voltage value. When the beam width at the anchoring point increases, the beam stiffness increases; thus, the pull-in voltage increases, and the opening time decreases. It should be noted that the optimum results presented in this paper are based on the use of gold as the switch material. Gold is chosen because of its ease of accessibility in most fabs. The optimum parameters are expected to vary if a different structural/contact material is used.

The two most promising results (easy to manufacture and have minimum constrictions, eliminating stress concentrations) are denoted by the numerals 1 and 8 in Fig. 6, and their corresponding geometry are in Figs. 7 and 8. These results have small opening time, reasonable pull-down voltage, and good power handling. Specifically, Figs. 7 and 8 show the lines connecting the beam optimized coordinates (i.e., beam geometry). Fig. 7 shows the design subject to minimum opening time due to its maximum stiffness, owing to its wide cross section at the anchoring point. Correspondingly, the required pull-down voltage is also large to overcome the switch stiffness. In contrast, Fig. 8 shows a design with longer opening time, three times longer, and having an anchoring point almost

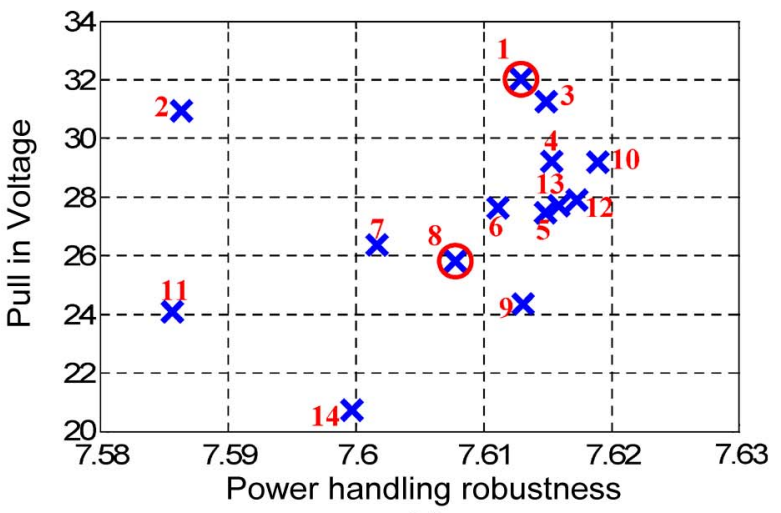

(a)

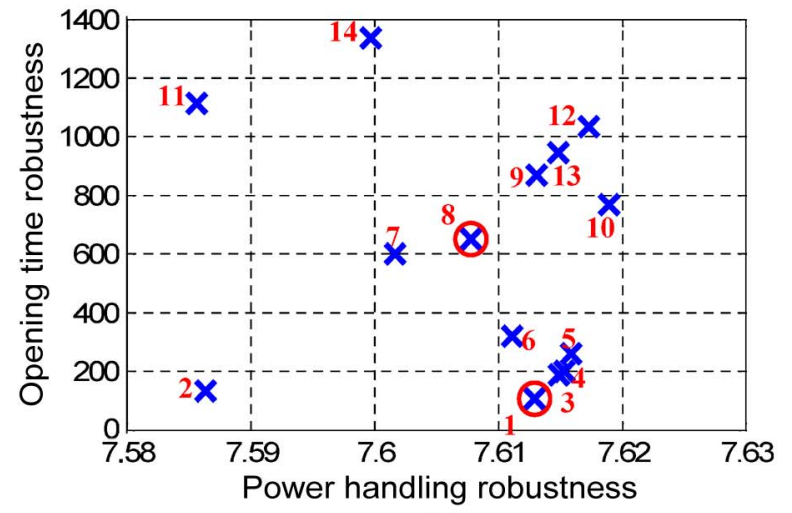

(b)

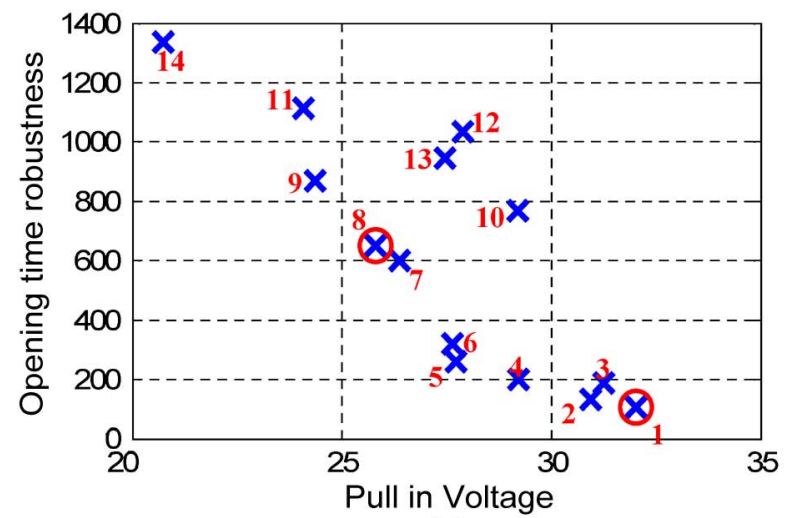

(c)

Fig. 6. Pareto solution projected in 2-D. (a) Power handling robustness versus pull-down voltage, (b) power handling robustness versus opening time robustness, and (c) pull-down voltage versus opening time robustness.

half the cross section of the previous solution. Of course, since the stiffness of the switch is lower, the pull-down voltage is much less. We remark that none of the designs have sharp edges that may cause stress concentration or issues with manufacturing.

The remaining 12 Pareto optimum results that have practical opening time and pull-down voltage results $(<50 \mu$ s and $<35 \mathrm{~V}$, respectively) are shown in the Appendix (Figs. 9-20). Although experimental validation is not given here, these results suggest that there is a substantial room for optimizing RF-MEMS switches to achieve a better performance than typical values such as opening time of $50 \mu \mathrm{s}-200 \mathrm{~ms}$, pull-down voltage of 50-80 V, and power handling of $20-50 \mathrm{~mW}$ [26]. 


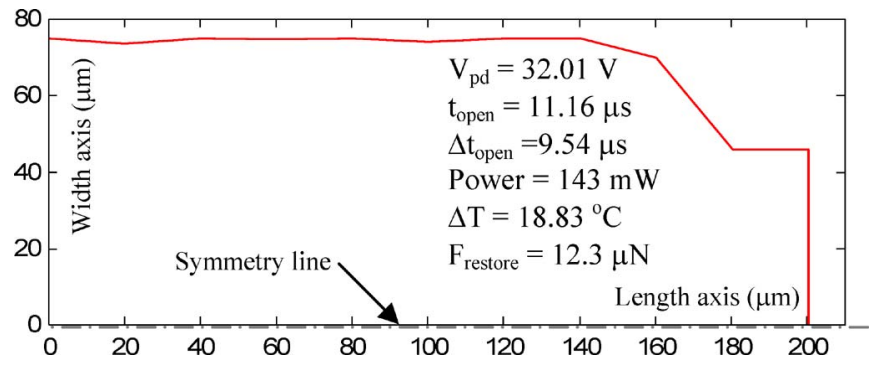

Fig. 7. Switch width (half shown) to achieve minimum opening time (Pareto point 1).

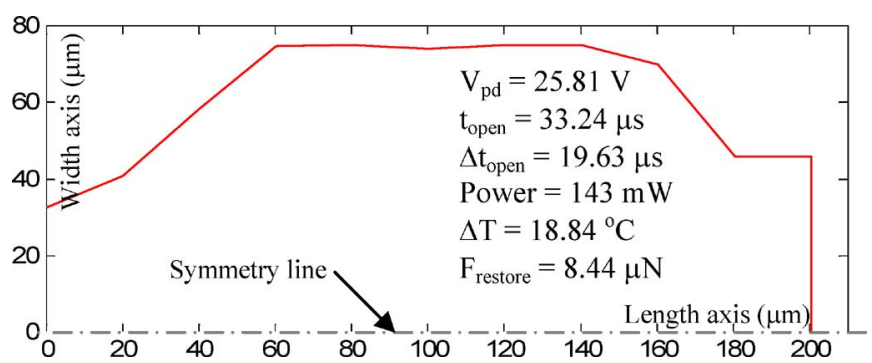

Fig. 8. Switch width (half shown) to achieve low pull-down voltage (Pareto point 8).

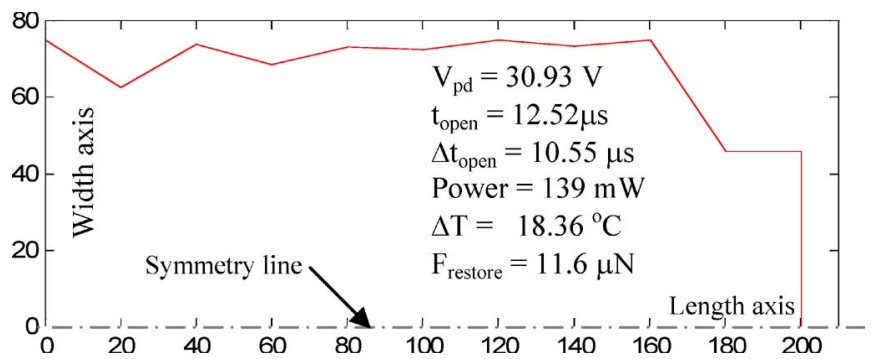

Fig. 9. Switch width (half shown) for Pareto Point 2.

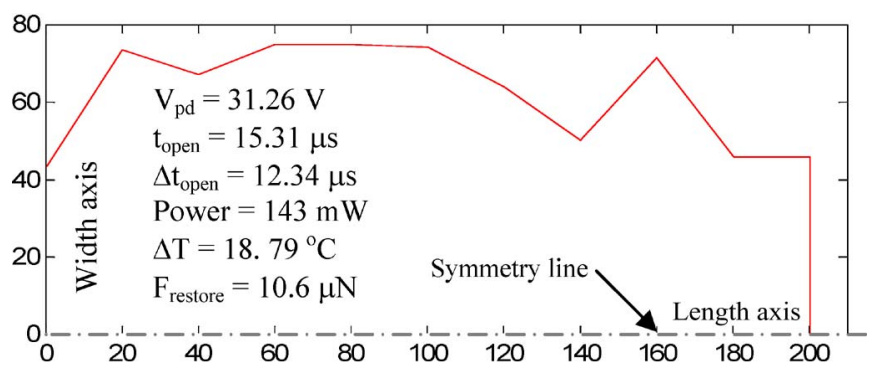

Fig. 10. Switch width (half shown) for Pareto Point 3.

\section{CONCLUSION AND RECOMMENDATIONS}

This paper presented a unique design method that utilizes variable multiphysics models (structural, contact adhesion, and thermal models combined together for the first time) to design an optimum RF-MEMS cantilever switches. The designed switches have low pull-down voltage, high power handling, and short opening time. The objectives were to minimize pull-down voltage and opening time, and maximize power handling. Solutions to the optimization problem were formulated using SPEA. The optimization algorithm utilizes the concept of robust optimization to minimize the effect of the variation of the

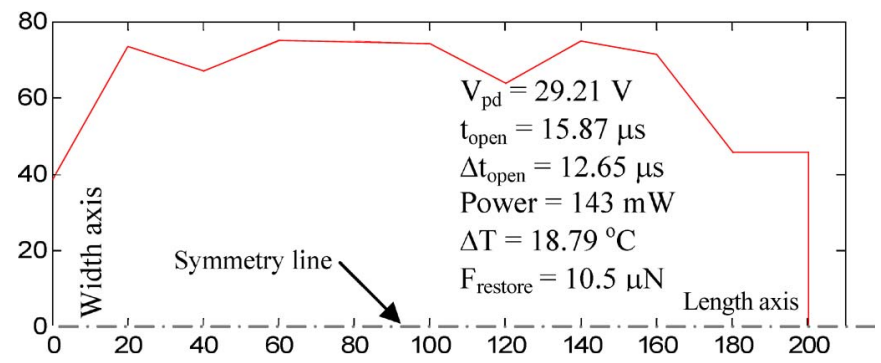

Fig. 11. Switch width (half shown) for Pareto Point 4.

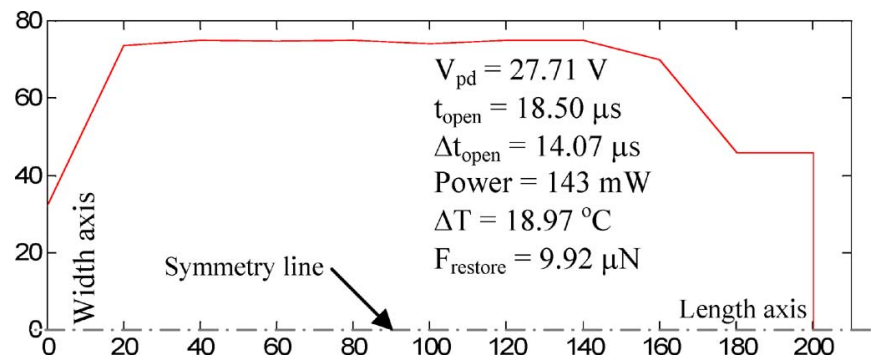

Fig. 12. Switch width (half shown) for Pareto Point 5.

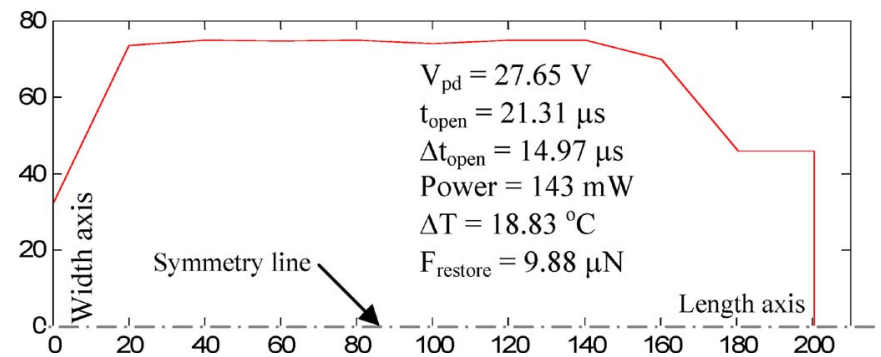

Fig. 13. Switch width (half shown) for Pareto Point 6.

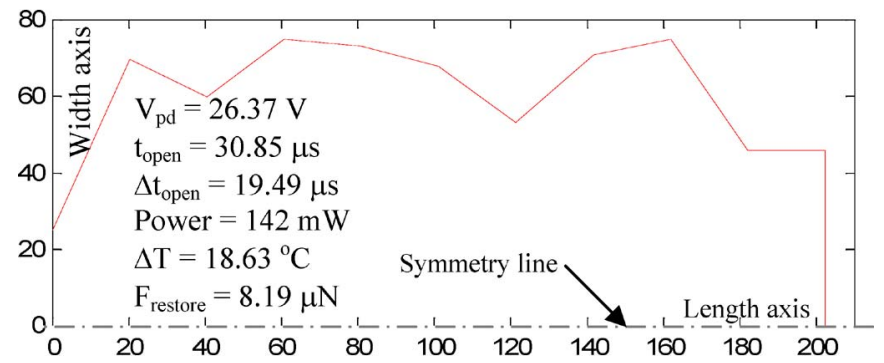

Fig. 14. Switch width (half shown) for Pareto Point 7.

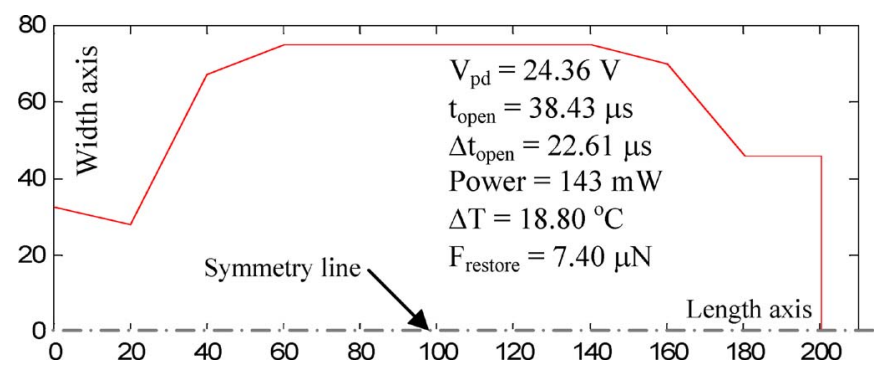

Fig. 15. Switch width (half shown) for Pareto Point 9.

contact resistance, which cannot be precisely controlled during the micromachining process, on the switch performance.

Based on the obtained results, the authors suggest the following rules for designing RF-MEMS cantilever switches. 1) Try to 


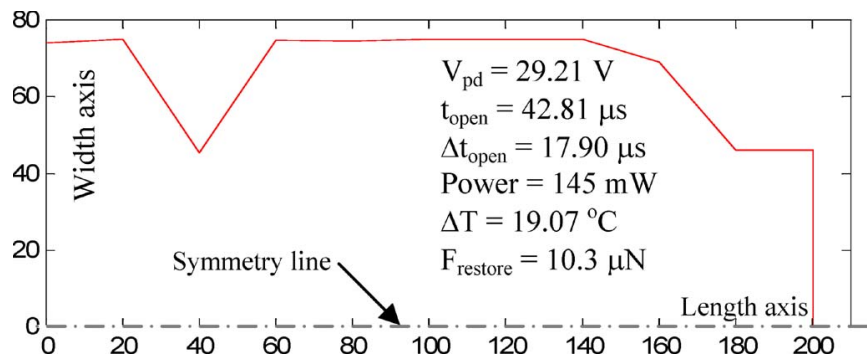

Fig. 16. Switch width (half shown) for Pareto Point 10.

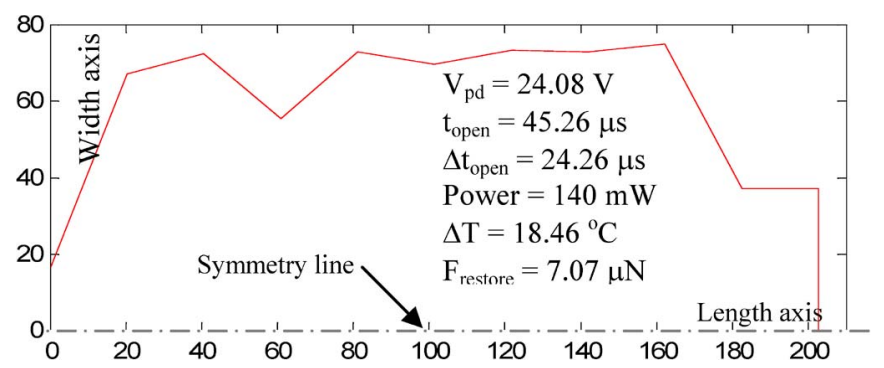

Fig. 17. Switch width (half shown) for Pareto Point 11

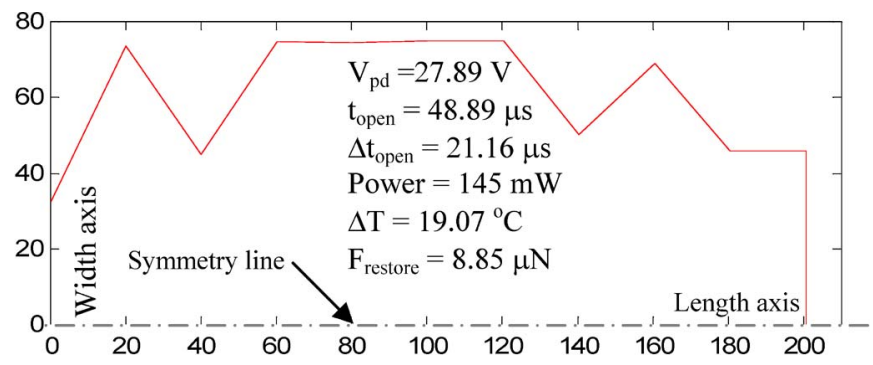

Fig. 18. Switch width (half shown) for Pareto Point 12.

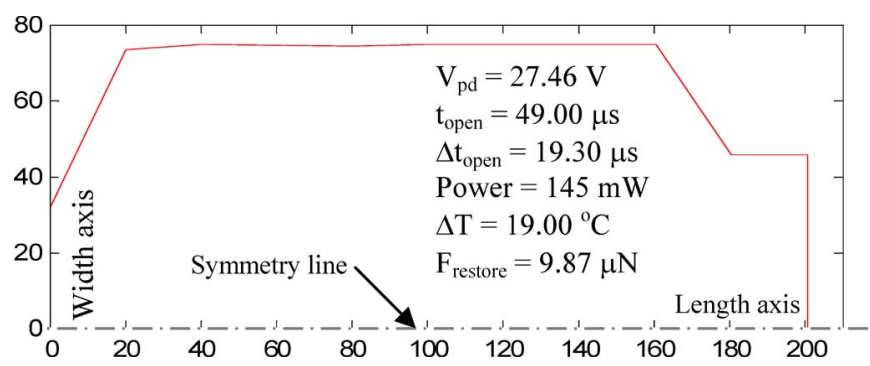

Fig. 19. Switch width (half shown) for Pareto Point 13

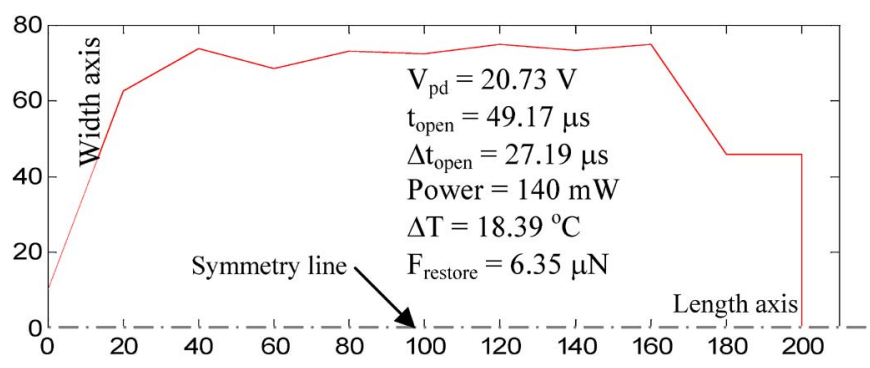

Fig. 20. Switch width (half shown) for Pareto Point 14

maximize the switch area above the actuation pad to minimize the actuation voltage. 2) If a larger beam width is used at the anchoring point, the opening time will decrease; yet, the pulldown voltage will increase and vice versa.
The results provided a better understanding of the key factors contributing to the performances of RF-MEMS switches. Most importantly, it provided guidance for further improvements of RF-MEMS switches that exploit complex multiphysics phenomena. In addition, introducing the concept of robust design in the MEMS field will open the area for more robust RF-MEMS cantilever switches that have optimum performance regardless of uncontrolled changes in the design parameters. This can help in implementing such switches in real-world applications without worrying about changes in performance during regular use.

As a future work, the authors intend to do finite element analysis on the optimized switches to better understand their performance. Also, the actual manufacturing and testing of the proposed switches is a next step to experimentally justify the simulation results achieved in this paper.

\section{APPENDIX}

See Figs. 9-20.

\section{REFERENCES}

[1] A. Frazier, R. Warrington, and C. Friedrich, "The miniaturization technologies: Past, present, and future," IEEE Trans. Ind. Electron., vol. 42, no. 5, pp. 423-430, Oct. 1995.

[2] G. Rebeiz, RF MEMS: Theory, Design, and Technology. Hoboken, NJ: Wiley, 2002.

[3] C. Goldsmith, Z. Yao, S. Eshelman, and D. Denniston, "Performance of low-loss RF MEMS capacitive switches," IEEE Microw. Guided Wave Lett., vol. 8, no. 8, pp. 269-271, Aug. 1998.

[4] D. Mercier, P. L. Charvet, P. Berruyer, C. Zanchi, L. Lapierre, O. Vendier, J. L. Cazaux, and P. Blondy, "A DC to $100 \mathrm{GHz}$ high performance ohmic shunt switch," in IEEE MTT-S Int. Microw. Symp. Tech. Dig., 2004, vol. 3 , pt. 3, pp. 1931-1934.

[5] B. Norvell, R. Hancock, J. Smith, M. Pugh, S. Theis, and J. Kviatkofsky, "Micro electro mechanical switch (MEMS) technology applied to electronically scanned arrays for space based radar," in Proc. Aerosp. Conf., Aspen, CO, 1999, vol. 3, pp. 239-247.

[6] C. W. Jung, M.-J. Lee, G. P. Li, and F. De Flaviis, "Reconfigurable scanbeam single-arm spiral antenna integrated with RF-MEMS switches," IEEE Trans. Antennas Propag., vol. 54, no. 2, pp. 455-463, Feb. 2006.

[7] R. N. Simons, D. Chun, and L. P. B. Katehi, "Polarization reconfigurable patch antenna using microelectromechanical systems (MEMS) actuators," in Proc. IEEE Antennas Propag. Soc. Int. Symp., 2002, vol. 2, pt. 2, pp. 6-9.

[8] N. Kingsley, G. Ponchak, and J. Papapolymerou, "Reconfigurable RF MEMS phased array antenna integrated within a liquid crystal polymer (LCP) system-on-package,"' IEEE Trans. Antennas Propag., vol. 56, no. 1, pp. 108-118, Jan. 2008.

[9] M. Daneshmand and R. Mansour, "Redundancy RF MEMS multiport switches and switch matrices," J. Microelectromech. Syst., vol. 16, no. 2, pp. 296-303, Apr. 2007.

[10] C. Goldmith, A. Malczewski, Z. Yao, S. Chen, J. Ehmke, and D. Hinzel, "RF MEMS variable capacitors for tunable filters," Int. J. RF Microw. Comput.-Aided Eng., vol. 9, pp. 362-374, Jul. 1999.

[11] G. K. Fedder and T. Mukherjee, "Tunable RF and analog circuits using onchip MEMS passive components," in Proc. IEEE Int. Solid-State Circuits Conf., 2005, vol. 1, pt. 1, pp. 390-391.

[12] S. Lee, J.-M. Kim, J.-M. Kim, J. K. Kim, and Y. W. Kwon, "Millimeterwave MEMS tunable low pass filter with reconfigurable series inductors and capacitive shunt switches," IEEE Microw. Wireless Compon. Lett. vol. 15 , no. 10 , pp. 691-693, Oct. 2005.

[13] J. DeNatale, "Reconfigurable RF circuits based on integrated MEMS switches," in Proc. IEEE ISSCC, 2004, pp. 310-311.

[14] B. D. Jensen, L. L. W. Chow, K. Huang, K. Saitou, J. L. Volakis, and K. Kurabayashi, "Effect of nanoscale heating on electrical transport in RF MEMS switch contacts," J. Microelectromech. Syst., vol. 14, no. 5, pp. 935-946, Oct. 2005. 
[15] B. Jensen, K. Huang, L. L.-W. Chow, and K. Kurabayashi, "Adhesion effects on contact opening dynamics in micromachined switches," J. Appl. Phys., vol. 97, no. 10, pp. 103 535-1-103 535-9, May 2005.

[16] G. Taguchi, Systems of Experimental Design. New York: Kraus Int., 1987.

[17] S. Tsutsui and A. Ghosh, "Genetic algorithms with a robust solution searching scheme," IEEE Trans. Evol. Comput., vol. 1, no. 3, pp. 201208, Sep. 1997.

[18] E. Zitzler and L. Thiele, "Multiobjective evolutionary algorithms: A comparative case study and the strength Pareto approach," IEEE Trans. Evol. Comput., vol. 3, no. 4, pp. 257-271, Nov. 1999.

[19] F. Mendoza, J. Bernal-Agustin, and J. Dominguez-Navarro, "NSGA and SPEA applied to multiobjective design of power distribution systems," IEEE Trans. Power Syst., vol. 21, no. 4, pp. 1938-1945, Nov. 2006.

[20] C. Coello, D. Veldhuizen, and G. Lamont, Evolutionary Algorithms for Solving Multi-Objective Problems. Norwell, MA: Kluwer, 2002.

[21] R. Chan, R. Lesnick, D. Becher, and M. Feng, "Low-actuation voltage RF MEMS shunt switch with cold switching lifetime of seven billion cycles," J. Microelectromech. Syst., vol. 12, no. 5, pp. 713-719, Oct. 2003.

[22] C. Goldsmith, J. Ehmke, A. Malczewski, B. Pillans, S. Eshelman, Z. Yao, J. Brank, and M. Eberly, "Lifetime characterization of capacitive RF MEMS switches," in IEEE MTT-S Int. Microw. Symp. Tech. Dig., Phoenix, AZ, 2001, vol. 3, pp. 227-230.

[23] C. Goldsmith, J. Maciel, and J. McKillop, "Demonstrating reliability," IEEE Microw. Mag., vol. 8, no. 6, pp. 56-60, Dec. 2007.

[24] C. Goldsmith, D. Forehand, Z. Peng, J. Hwang, and I. Ebel, "High-cycle life testing of RF MEMS switches," in IEEE MTT-S Int. Microw. Symp. Tech. Dig., Jun. 2007, pp. 1805-1808.

[25] B. Schauwecker, K. Strohm, W. Simon, J. Mehner, and J. Luy, "Toggleswitch-A new type of RF MEMS switch for power applications," in IEEE MTT-S Int. Microw. Symp. Tech. Dig., Seattle, WA, 2002, vol. 1, pp. 219-222.

[26] G. Rebeiz and J. Muldavin, "RF MEMS switches and switch circuits," IEEE Microw. Mag., vol. 2, no. 4, pp. 59-71, Dec. 2001.

[27] Z. Wang, B. Jensen, L. L.-W. Chow, J. Volakis, K. Saitou, and K. Kurabayashi, "Full-wave electromagnetic and thermal modeling for the prediction of heat-dissipation-induced RF-MEMS switch failure," J. Micromech. Microeng., vol. 16, no. 1, pp. 157-164, Jan. 2006.

[28] W. Thiel, K. Tornquist, R. Reano, and L. Katehi, "A study of thermal effects in RF-MEM-switches using a time domain approach," in IEEE MTT-S Int. Microw. Symp. Tech. Dig., Seattle, WA, 2002, pp. 235-238.

[29] J. Volakis, A. Chatterjee, and L. Kempel, Finite Element Method of Electromagnetics. New York: IEEE Press, 1998.

[30] L. L.-W. Chow, Z. Wang, B. Jensen, K. Saitou, J. Volakis, and K. Kurabayashi, "Skin-effect self-heating in air-suspended RF MEMS transmission-line structures," J. Microelectromech. Syst., vol. 15, no. 6, pp. 1622-1631, Dec. 2006.

[31] J. A. Greenwood and J. B. P. Williamson, "Electrical conduction in solids. II. Theory of temperature-dependent conductors," Proc. R. Soc. Lond. A, Math. Phys. Sci., vol. 246, no. 1244, pp. 13-31, Jul. 1958.

[32] B. Ducarouge, D. Dubuc, S. Melle, K. Grenier, L. Mazenq, L. Bary, and R. Plana, "Efficient topology and design methodology for RF MEMS switches," in Proc. SPIE-Int. Soc. Opt. Eng., Smart Sens., Actuators, MEMS II, Seville, Spain, May 9-11, 2005, vol. 5836, pp. 535-539.

[33] M. Miao, Z. Xiao, G. Wu, Y. Hao, and H. Zhang, "Capacitive RF MEMS switch with composite beam," in Proc. SPIE-Int. Soc. Opt. Eng., MEMS/MOEMS Technol. Appl., China, Oct. 17-18, 2002, vol. 4928, pp. 248-255

[34] J. Huang, K. Liew, C. Wong, S. Rajendran, M. Tan, and A. Liu, "Mechanical design and optimization of capacitive micromachined switch," Sens. Actuators A, Phys., vol. 93, no. 3, pp. 273-285, Oct. 2001.

[35] Y. Lee and D. Filipovic, "ANN based electromagnetic models for the design of RF MEMS switches," IEEE Microw. Wireless Compon. Lett., vol. 15 , no. 11 , pp. 823-825, Nov. 2005.

[36] J. Che, G. Xian, and E. Knod, "An integrated design method of new product and the production process based on Taguchi robust design," in Proc. 2nd IEEE Conf. Ind. Electron. Appl., Harbin, China, May 23-25, 2007, pp. 1437-1442.

[37] R. Al-Aomar, "Incorporating robustness into genetic algorithm search of stochastic simulation outputs," Simul. Model. Pract. Theory, vol. 14, no. 3, pp. 201-223, Apr. 2006.

[38] I. Madu and C. Madu, "Design optimization using signal-to-noise ratio," Simul. Pract. Theory, vol. 7, no. 4, pp. 349-372, Jun. 1999.

[39] W. Fowlkes and M. Clyde, Engineering Methods for Robust Product Design. Reading, MA: Addison-Wesley, 1995.

[40] B. Ramakrishnan and S. Rao, "A robust optimization approach using Taguchi's loss function for solving nonlinear optimization problems,"
ASME Des. Eng. Div. Publ. DE, Adv. Des. Autom., vol. 1, no. 32, pp. 241248, Sep. 22-25, 1991.

[41] F. Gardiol, Microstrip Circuits. New York: Wiley, 1994.

[42] MATLAB R14 V7.1, 1984-2005, Natick, MA: MathWorks, Inc. [Online]. Available: www.mathworks.com

[43] G. Forsythe, M. Malcolm, and C. Moler, Computer Methods for Mathematical Computations. Englewood Cliffs, NJ: Prentice-Hall, 1976.

[44] G. Rubio-Bollinger, S. R. Bahn, N. Agraï, K. W. Jacobsen, and S. Vieira, "Mechanical properties and formation mechanisms of a wire of single gold atoms," Phys. Rev. Lett., vol. 87, no. 2, pp. 026 101-1-026 101-2, Jul. 2001.

[45] B. Nikolić and P. Allen, "Electron transport through a circular constriction," Phys. Rev. B, Condens. Matter, vol. 60, no. 6, pp. 3963-3969, Aug. 1999.

[46] R. Timsit, "Electrical contact resistance: Properties of stationary interfaces," IEEE Trans. Compon. Packag. Technol., vol. 22, no. 1, pp. 85-98, Mar. 1999.

[47] R. Holm, Electrical Contacts, Theory and Applications. Berlin, Germany: Springer-Verlag, 1976.

[48] B. Jensen, K. Huang, L. L.-W. Chow, and K. Kurabayashi, "Lowforce contact heating and softening using micromechanical switches in diffusive-ballistic electron-transport transition," Appl. Phys. Lett., vol. 86, no. 2, pp. 023 507-1-023 507-3, Jan. 2005.

[49] Z. Wang, "Integrated electromagnetic/thermal/mechanical analysis and optimization design of RF-MEMS switches," Ph.D. dissertation, Univ. Michigan, Ann Arbor, MI, 2005.

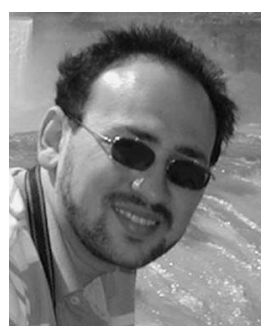

Mohammed M. Shalaby received the B.S. and M.S degrees from Cairo University, Cairo, Egypt, in 2000 and 2002, respectively, and the Ph.D. degree from the University of Michigan, Ann Arbor, in 2008, all in mechanical engineering.

Since February 2008, he has been with the Global Research Center, General Electric Company, Niskayuna, NY, as a Mechanical Engineer in the Mechanical Integration and Operability Laboratory. $\mathrm{He}$ has published over 20 conference/journal papers in the areas of design for disassembly, RF-MEMS, and reverse engineering. His current research interests are developing CAD tools for the automation of the design process, design automation and optimization, design for disassembly, and optimization of MEMS components.

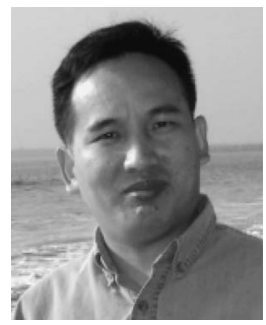

Zhongde Wang (M'04) received the M.S. degree from the University of Waterloo, Waterloo, ON, Canada, in 2002, and the Ph.D. degree from the University of Michigan, Ann Arbor, in 2005, both in electrical engineering.

Since January 2005, he has been with Ansoft Corporation (now part of Ansys Inc.), San Jose, $\mathrm{CA}$, as an Application Engineer. He has authored or coauthored over 20 technical papers. His current research focuses on computational electromagnetics with applications in antenna/microwave component design, RF-MEMS switches, the signal and power integrities of printed circuit boards and packages, etc.

Dr. Wang was the recipient of the second-grade prize of the Science and Technology Progress awarded by the Chinese Electrical Ministry in 1996.

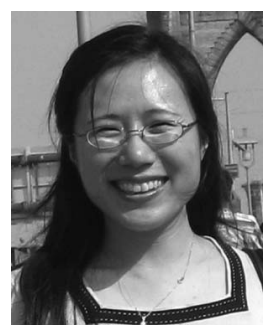

Linda L.-W. Chow (S'02-M'06) received the Ph.D. degree from the University of Michigan, Ann Arbor, in 2006 .

She has been a Packaging Engineer with Intel Corporation, Phoenix, AZ, since her graduation. She has published over 20 conference/journal papers in the areas of sensors, RF-MEMS, packaging, and reliability physics. She is also the holder of two patents, one pending patent, and three trade secrets.

Dr. Chow was awarded with Best Teaching Assistant twice and Best Student Paper at the IEEE International Symposium on Electronic Materials and Packaging in 2000 


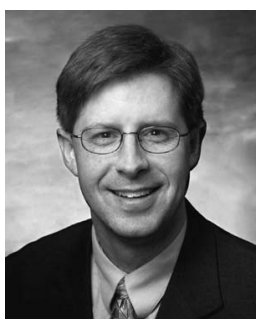

Brian D. Jensen received the B.S. and M.S. degrees in mechanical engineering from Brigham Young University, Provo, UT, in 1996 and 1998, respectively, and the M.S. and Ph.D. degrees in electrical and mechanical engineering, respectively, from the University of Michigan, Ann Arbor, both in 2004.

He has been with the Department of Mechanical Engineering, Brigham Young University, since January 2005. In 1998 and 1999, he spent 16 months as a Micromechanism Designer with Sandia National Laboratories, Albuquerque, NM. He has performed research and published over 50 papers on a wide variety of design topics, including microelectromechanical systems and compliant mechanisms, and he is the holder of seven U.S. patents.

Dr. Jensen was the recipient of a National Science Foundation Graduate Research Fellowship and a Department of Defense Science and Engineering Graduate Fellowship.

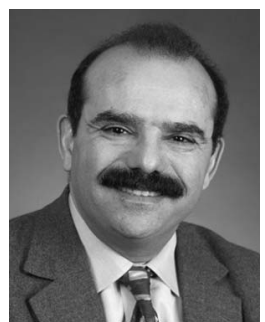

John L. Volakis (S'77-M'82-SM'89-F'96) was born on May 13, 1956 in Chios, Greece, and immigrated to the U.S. in 1973. He received the B.E. degree (summa cum laude) from Youngstown State University, Youngstown, OH, in 1978, and the M.Sc. and $\mathrm{Ph} . \mathrm{D}$. degrees from The Ohio State University, Columbus, in 1979 and 1982, respectively.

He was with Rockwell International (1982-1984), now Boeing Phantom Works, Seal Beach, CA. In 1984, he was appointed Assistant Professor at the University of Michigan (UM), Ann Arbor, becoming a Full Professor in 1994. He was also the Director of the Radiation Laboratory from 1998 to 2000. Since January 2003, he has been the Roy and Lois Chope Chair Professor of Engineering with The Ohio State University and the Director of the ElectroScience Laboratory, Department of Electrical and Computer Engineering. He has published over 250 articles in major refereed journals, nearly 380 conference papers, and 20 book chapters. He is a coauthor of the following four books: Approximate Boundary Conditions in Electromagnetics (IEE, 1995), Finite Element Method for Electromagnetics (IEEE Press, 1998), Frequency Domain Hybrid Finite Element Methods in Electromagnetics (Morgan \& Claypool, 2006), and Antenna Engineering Handbook (McGraw-Hill, 2007), of which he was also the Editor. He was the Associate Editor of Radio Science from 1994 to 1997 and, currently, is an Associate Editor for the Journal of Electromagnetic Waves and Applications and the Union Radio Scientific International (URSI) Bulletin. He has also written several well-edited coursepacks on introductory and advanced numerical methods for electromagnetics and has delivered short courses on antennas, numerical methods, and frequencyselective surfaces. He is listed by ISI Web of Knowledge among the top 250 most referenced authors. He graduated/mentored nearly $60 \mathrm{Ph} . D$. students/ postdocs and coauthored with them nine papers that received best paper awards at conferences. His primary research deals with antennas, computational methods, electromagnetic compatibility and interference, propagation, design optimization, RF materials, multiphysics engineering, and bioelectromagnetics.

Dr. Volakis is a member of the URSI Commissions B and E. He was the 2004 President of the IEEE Antennas and Propagation Society and served on the AdCom of the IEEE Antennas and Propagation Society from 1995 to 1998. He also served as Associate Editor for the IEEE TRANSACTIONS ON ANTENNAS AND PROPAGATION from 1988 to 1992 and for the IEEE Antennas and Propagation Magazine (1992-2006). He chaired the 1993 IEEE Antennas and Propagation Society Symposium and Radio Science Meeting in Ann Arbor, MI, and cochaired the same symposium in 2003 in Columbus, OH. He was the recipient of the UM College of Engineering Research Excellence Award in 1998 and the UM Department of Electrical Engineering and Computer Science Service Excellence Award in 2001.

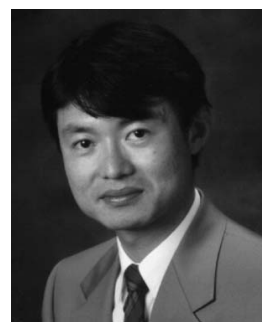

Katsuo Kurabayashi (M'00) received the B.S. degree in precision engineering from the University of Tokyo, Tokyo, Japan, in 1992, and the M.S. and $\mathrm{Ph} . \mathrm{D}$. degrees in materials science and engineering with electrical engineering minor from Stanford University, Stanford, CA, in 1994 and 1998, respectively. His dissertation work focused on the measurement and modeling of the thermal transport properties of electronic packaging and organic materials for integrated circuits under a contract with the Semiconductor Research Corporation (SRC).

Upon completion of his Ph.D. program, he was a Research Associate with the Department of Mechanical Engineering, Stanford University, for 12 months. Since January 2000, he has been with the faculty of the University of Michigan, Ann Arbor, where he is currently an Associate Professor of Mechanical Engineering and Electrical Engineering and Computer Science in the Department of Mechanical Engineering. His group at Michigan studies MEMS-based molecular imaging and detection, integration of nanoscale biomolecules into microsystems, ultrafast thermal modulation for micro gas chromatography, and novel cell/protein patterning. He was a Visiting Professor at the Tokyo Institute of Technology in 2006.

Dr. Kurabayashi was a recipient of the SRC Best Paper Award (1998), the National Science Foundation CAREER Award (2001), the University of Michigan Robert Caddell Memorial Award (2004), and the Pi Tau Sigma Outstanding Professor Award (2007).

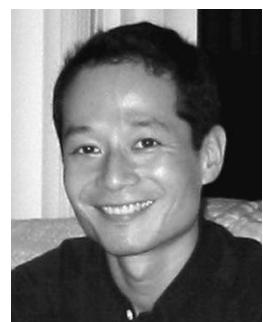

Kazuhiro Saitou (M'97-SM'07) received the B.S. degree from the University of Tokyo, Tokyo, Japan, in 1990, and the M.S. and Ph.D. degrees from the Massachusetts Institute of Technology, Cambridge, in 1992 and 1996, respectively, all in mechanical engineering.

From 1997 to 2003, he was an Assistant Professor with the Department of Mechanical Engineering, University of Michigan, Ann Arbor, where he is currently an Associate Professor. His research interest is the algorithmic and optimal synthesis of products and systems, including product/supply chain codesign, optimal synthesis of MEMS/nanoelectromechanical systems, chemo-/bioinformatics, and structurebased virtual screening in drug design.

Dr. Saitou is a member of the American Society of Mechanical Engineers (ASME) and a Senior Member of the Society of Manufacturing Engineers. He currently serves as an Associate Editor for the IEEE TRANSACTIONS ON Automation SCIENCE AND ENGINEERING, the Vice Chair of the ASME Design for Manufacturing Technical Committee, and a member of the ASME Design Automation Conference Executive Committee. He was the Organizing Chair of the 2007 IEEE International Symposium on Assembly and Manufacturing, and the Program Chair of the 2008 IEEE Conference on Automation Science and Engineering and the 2008 ASME Design Automation Conference. He was the recipient of a 1999 CAREER Award from the National Science Foundation, the Best Paper Award at the 5th International Symposium on Tools and Methods of Competitive Engineering in 2004, and the Outstanding Achievement Award from the Department of Mechanical Engineering, University of Michigan, in 2007, and was one of the finalists for the Best Paper Awards at EcoDesign: 4th International Symposium on Environmentally Conscious Design and Inverse Manufacturing in 2005 and the IEEE Conference on Automation Science and Engineering in 2006. 